\title{
A FRAÇÃo VOLÁTIL DAS AGUARDENTES DE CANA PRODUZIDAS NO BRASIL
}

\section{Ricardo F. A. Moreira, Claudia C. Netto e Carlos A. B. de Maria*}

Departamento de Bioquímica, Instituto Biomédico, Universidade Federal do Estado do Rio de Janeiro, Rua Frei Caneca, 94, 20211-040 Rio de Janeiro - RJ, Brasil

Recebido em 15/7/11; aceito em 20/4/12; publicado na web em 10/8/12

THE VOLATILE FRACTION OF SUGAR CANE SPIRITS PRODUCED IN BRAZIL. The volatile fraction of sugar cane spirits plays a key role in the quality and acceptance of these beverages. The composition of this fraction is dependent on the way sugar cane collection, fermentation, distillation and aging are carried out. The materials used in these processes strongly influence chemical composition. Acetic acid, acetaldehyde, ethyl acetate, ethanol, 2.3-butanedione, $n$-propanol, 3-methyl-buthanol and isobuthanol were the major volatiles in spirits. Dimethyl sulfide and $n$-propanol impaired beverage flavor. Ethyl octanoate, 1.1-diethoxy-ethane, 2-phenylethanol and 3-methyl-butanol were important aroma contributors. Ageing allows the extraction of flavor-active components (e.g., phenolic compounds) from wood.

Keywords: sugar cane spirit; volatile compounds; flavor.

\section{INTRODUÇÃO}

\section{Definição}

O Decreto Federal 4.851 de 2003, baseado na portaria 371 do Decreto original número 2314, de 04/09/1997, dispõe sobre a padronização, classificação, registro, inspeção, produção e a fiscalização de bebidas. De acordo com este decreto e complementado pela Instrução Normativa de $n^{\circ} 13$ de 30/06/2005 do Ministério da Agricultura, Pecuária e Abastecimento (MAPA), aguardente de cana é a bebida com graduação alcoólica entre 38 e $54 \%$ v/v a $20{ }^{\circ} \mathrm{C}$ obtida do destilado alcoólico simples de cana-de-açúcar (Saccharum officinarum L.) ou pela destilação do mosto fermentado do caldo de cana-de-açúcar, podendo ser adicionada de açúcares em até $6,0 \mathrm{~g} \mathrm{~L}^{-1}$, expressos em sacarose. Já cachaça é a denominação típica e exclusiva da aguardente de cana produzida no Brasil, com graduação alcoólica entre 38 e $48 \%$ v/v a $20^{\circ} \mathrm{C}$, obtida pela destilação do mosto fermentado do caldo de cana-de-açúcar, com características sensoriais peculiares, podendo ser adicionada de açúcares em até $6,0 \mathrm{~g} \mathrm{~L}^{-1}$, expressos em sacarose. Visando proteger a marca brasileira no cenário internacional, o artigo 92 dessa Lei define que a cachaça é um produto genuinamente brasileiro. ${ }^{1}$ Outras denominações específicas (por exemplo, aguardente de cana envelhecida, aguardente de cana Premium) também podem ser atribuídas a certas aguardentes de cana brasileiras, de acordo com a legislação. ${ }^{1}$ Os padrões de identidade e qualidade (PIQs) para aguardente de cana-de-açúcar e para cachaça foram estabelecidos pela legislação brasileira no supracitado Decreto (4.851 de 2003). ${ }^{1}$ Posteriormente, esses padrões foram reavaliados e os limites de alguns componentes e contaminantes foram mantidos e os de outros foram acrescentados, de acordo com a Instrução Normativa ${ }^{\circ} 13$ de 2005, também mencionada anteriormente (Tabela 1). ${ }^{1}$

\section{Justificativa e objetivos}

Os dados compilados pela Associação Brasileira de Bebidas (ABRABE) mostram que foram produzidos 1,3 bilhões de litros por ano de aguardente de cana no Brasil em 2003. ${ }^{2}$ As exportações ficaram em torno de 15 milhões de litros e atenderam 70 países, sendo

*e-mail: carreb@uol.com.br
Tabela 1. Padrões de identidade e qualidade para cachaça e aguardente de cana

\begin{tabular}{lcc}
\hline Componente & Unidade & Limite \\
\hline Teor de etanol em aguardente & $\%$ em v/v de etanol a $20{ }^{\circ} \mathrm{C}$ & $38-54$ \\
Teor de etanol em cachaça & $\%$ em v/v de etanol a $20{ }^{\circ} \mathrm{C}$ & $38-48$ \\
Sacarose em açúcar cristal & $\mathrm{g} \mathrm{L}{ }^{-1}$ & $6,0-30$ \\
Acidez volátil e ácido acético & $\mathrm{mg} 100 \mathrm{~mL}^{-1}$ álcool anidro & 150 \\
Ésteres, em acetato de etila & $\mathrm{mg} 100 \mathrm{~mL}^{-1}$ álcool anidro & 200 \\
Aldeídos, em aldeído acético & $\mathrm{mg} 100 \mathrm{~mL}^{-1}$ álcool anidro & 30 \\
Soma de furfural em HMF & $\mathrm{mg} 100 \mathrm{~mL}^{-1}$ álcool anidro & 5 \\
Alcoóis superiores & $\mathrm{mg} 100 \mathrm{~mL}^{-1}$ álcool anidro & 360 \\
Congêneres** & $\mathrm{mg} 100 \mathrm{~mL}^{-1}$ álcool anidro & $200-650$ \\
Álcool metílico & $\mathrm{mg} 100 \mathrm{~mL}^{-1}$ álcool anidro & 20 \\
Cobre & $\mathrm{mg} \mathrm{L}^{-1}$ & 5 \\
Chumbo & $\mu \mathrm{g} \mathrm{L}^{-1}$ & 200 \\
Arsênio & $\mu \mathrm{g} \mathrm{L}^{-1}$ & 100 \\
Extrato seco & $\mathrm{g} \mathrm{L}^{-1}$ & 6 \\
Carbamato de etila & $\mu \mathrm{g} \mathrm{L}^{-1}$ & 150 \\
Acroleína & $\mathrm{mg} 100 \mathrm{~mL}^{-1}$ álcool anidro & 5 \\
Butanol-2 & $\mathrm{mg} 100 \mathrm{~mL}^{-1}$ álcool anidro & 10 \\
Butanol-1 & $\mathrm{mg} 100 \mathrm{~mL}^{-1}$ álcool anidro & 3 \\
\hline & & 510
\end{tabular}

"Alcoóis superiores $=($ isobutílico + isoamílico + propílico $), \mathrm{HMF}=$ hidroximetilfurfural, ${ }^{* *}$ Congêneres $=($ acidez volátil + ésteres + aldeídos + furfural + alcoóis superiores), ${ }^{* * *}$ Aguardente de cana e cachaça "adoçada" = máximo 30,0 g/L. Extraído da ref. 1

a Alemanha o principal importador. Isso vem gerando um lucro para o Brasil de cerca de US\$ 9 milhões por ano. ${ }^{2,3}$ A cota de exportação ainda é pequena (cerca de 1\%) se comparada à produção, mas com enorme potencial a ser explorado, devido ao sucesso comprovado da aguardente de cana e da cachaça no mundo.

O estabelecimento de um controle de qualidade químico e sensorial é condição essencial para que esses produtos brasileiros possam competir em condições de igualdade com outras bebidas fermento-destiladas no mercado internacional. As características 
sensoriais desse tipo de bebida dependem de alguns fatores, dentre estes a fração volátil assume papel preponderante. Dessa forma, este trabalho de revisão foi realizado com o intuito de prover informações sobre a composição da fração volátil das aguardentes de cana produzidas no Brasil. É importante frisar que durante o processo de revisão da literatura para a realização dessa obra, os autores consultaram informações sobre a fração volátil das aguardentes de cana produzidas e comercializadas no Brasil sem, entretanto, fazer distinção entre aquelas bebidas que poderiam ser classificadas como cachaça e as demais que não poderiam se encaixar nesse grupo, com base em seus teores de etanol.

\section{FRAÇÃO VOLÁTIL}

\section{Composição global e origem dos compostos voláteis das aguardentes}

Os alcoóis, ácidos e ésteres formam, quantitativa e qualitativamente, os maiores grupos presentes na fração volátil das bebidas alcoólicas. Os compostos carbonílicos (ex. aldeídos e cetonas), acetais, compostos sulfurados e fenóis são minoritários, mas podem ter grande importância para o aroma e sabor desses produtos. ${ }^{4,5}$

As rotas químicas e bioquímicas responsáveis pela formação dos compostos voláteis em alimentos também agem nas bebidas, havendo variações conforme as características intrínsecas de cada matriz e o tipo de processamento a que cada uma foi submetida. As vias catabólicas que contribuem para formação da fração volátil em bebidas alcoólicas são mostradas na Figura $1 .^{6}$

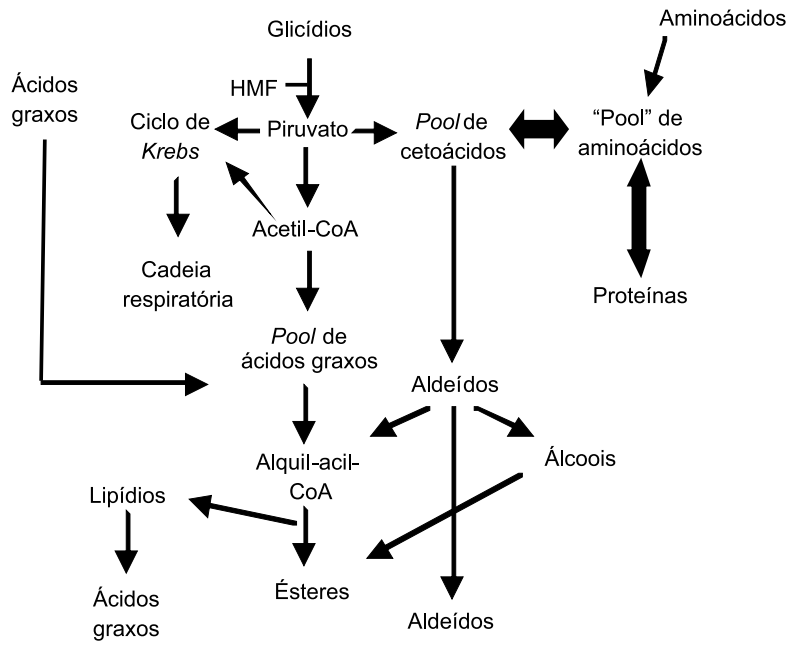

Figura 1. Rotas de formação dos compostos voláteis de alguns dos diferentes grupos químicos. Modificada da ref. 6

Os alcoóis são formados indiretamente a partir da degradação de glicídios e aminoácidos. Os $\alpha$-cetoácidos formados durante a degradação desses constituintes são reduzidos a aldeídos que, por sua vez, são reduzidos a alcoóis. ${ }^{7}$ Os aldeídos são formados a partir da degradação oxidativa de aminoácidos, oxidação de alcoóis ou auto-oxidação de ácidos graxos. ${ }^{7}$ A desidratação térmica de glicídios é uma reação que também forma aldeídos, na qual pentoses formam furfural como principal produto de degradação e hexoses formam o 5-hidroximetilfurfural (HMF). A quebra da cadeia de carbono dos produtos primários da desidratação de glicídios pode formar outros compostos, tais como, ácido acético, acetoína e diacetila. Alguns desses compostos são voláteis e poderiam ter influência sobre o aroma de alimentos e bebidas. ${ }^{8} \mathrm{~A}$ origem das cetonas nas aguardentes de cana está relacionada a processos de fermentação secundários e possível contaminação durante a produção. ${ }^{9}$ A produção de cetonas, como a 2,3-butanodiona, também pode ser explicada, por exemplo, pela auto-oxidação de lipídios, particularmente de ácidos graxos insaturados. ${ }^{10} \mathrm{~A} 2,3$-butanodiona também é considerada um produto secundário da reação de Maillard. ${ }^{10}$ Os ésteres e ácidos graxos são formados principalmente pela ação de leveduras via esterificação de ácidos graxos e/ou degradação de aminoácidos. ${ }^{11}$ Os ácidos graxos, sintetizados a partir do piruvato e de outros $\alpha$-cetoácidos, são ativados pela coenzima A (CoA) formando os derivados acil-CoA. Após a saída do complexo enzimático da acil-CoA carboxilase, os derivados acil-CoA reagem com alcoóis formando ésteres. ${ }^{7} \mathrm{O}$ teor de ésteres produzidos depende do conteúdo relativo de alcoóis correspondentes e de acil-CoA. A formação de ésteres pós-fermentação alcoólica, via reação direta entre alcoóis e ácidos, também ocorre, porém em escala bem menor que a via enzimática. ${ }^{12} \mathrm{~A}$ síntese de ácidos graxos e de outros ácidos orgânicos ocorre via metabolismo intermediário de aminoácidos a partir de $\alpha$-cetoácidos e do metabolismo de glicídios em reações do ciclo de Krebs. ${ }^{13}$ Os acetais são formados através da reação entre aldeídos e alcoóis. Por exemplo, o 1,1-dietóxi-etano é formado pela reação de adição entre o acetaldeído e o etanol, formando um hemiacetal que, em seguida, sofre condensação com outra molécula de etanol. ${ }^{12}$ Já a origem dos compostos sulfurados pode estar relacionada tanto ao metabolismo microbiano como, também, à degradação dos aminoácidos sulfurados (metionina e cisteína) de proteínas da levedura. ${ }^{14}$ Por último, a presença de compostos fenólicos (por ex., ácidos fenólicos) nas aguardentes de cana está majoritariamente associada ao processo de envelhecimento dessas bebidas em barris de madeira, a partir dos quais estes compostos são lentamente extraídos. ${ }^{15}$

A seguir, discutem-se mais detalhadamente os principais grupos de compostos presentes na fração volátil das aguardentes de cana brasileiras.

\section{Alcoóis}

A fermentação alcoólica do caldo da cana-de-açúcar produz etanol como principal produto. Devido ao seu alto valor de limiar de odor (100.000 ppb) e sua característica de aroma pouco marcante, apesar do seu alto teor nas aguardentes, esse álcool é provavelmente um dos componentes voláteis de menor destaque no aroma dessas bebidas. ${ }^{12}$ As aguardentes de cana também podem conter pequenas quantidades de metanol como contaminante. Sua presença pode estar ligada a uma filtração inadequada do caldo, o que possibilita a presença de bagacilhos no processo fermentativo, cuja pequena quantidade de pectina pode ser degradada (em condições ácidas) dando origem ao metanol. ${ }^{16} \mathrm{~A}$ presença dessa substância é indesejada nas bebidas alcoólicas, pois pode causar sintomas tóxicos como, por exemplo, dor de cabeça, vertigem e vômitos. Além disso, se ingerido durante longo período, mesmo em doses pequenas, pode levar o indivíduo à cegueira e até mesmo à morte, pois provoca acidose e disfunção celular. ${ }^{16-18}$ Além dos alcoóis supracitados, os alcoóis superiores com 3 a 5 átomos de carbono (por ex., 2-metilbutanol-1, 3-metilbutanol-1, pentanol, 2-metilpropanol-1 e propanol) são frequentemente encontrados em bebidas destiladas, sendo os principais representantes do grupo de compostos minoritários das aguardentes de cana (compostos secundários). ${ }^{16,19}$ Esses alcoóis são conhecidos como "óleo fúsel”, sua produção parece ser uma característica das leveduras em geral e as quantidades produzidas variam com as condições de fermentação, o gênero, a espécie e, provavelmente, a cepa utilizada. ${ }^{16}$ Esses alcoóis superiores costumam ter grande influência sobre o sabor das bebidas alcoólicas, apresentando odores característicos tradicionalmente associados às mesmas. ${ }^{17} \mathrm{O} 3$-metilbutanol-1 (álcool isoamílico), por exemplo, tem seu odor caracterizado como "uísque" e "malte", além de "alcoólico", "vínico", "banana" e "doce". ${ }^{12}$ Nesse 
aspecto, deve-se lembrar que as características de odor dos compostos voláteis dependem de suas concentrações, de forma que quantidades muito elevadas podem modificar características de odor consideradas agradáveis para extremamente desagradáveis. ${ }^{12}$ Alguns autores descrevem, por exemplo, que grandes quantidades de óleo fúsel diminuem o valor comercial e a qualidade das cachaças e que o teor desses alcoóis superiores normalmente deve acompanhar proporcionalmente os ésteres em uma cachaça de boa qualidade. ${ }^{16}$ Existem, ainda, alguns estudos sobre a correlação entre os teores de $n$-propanol e a qualidade sensorial das bebidas alcoólicas. ${ }^{20}$ Foi relatada a ocorrência de maiores teores de $n$-propanol e de acidez em bebidas fermento-destiladas de qualidade inferior. Em virtude das características físicas do $n$-propanol, o mesmo destila durante a primeira destilação com alto grau de uniformidade, sendo a variação dos teores de $n$-propanol entre as frações inicial e final da destilação (frações que destilam a 81 e a $42 \%$ de álcool em volume a $20{ }^{\circ} \mathrm{C}$, respectivamente) em torno de $8 \% .{ }^{20}$ Alguns alcoóis superiores com mais de cinco átomos de carbono, por exemplo, 2-feniletanol, lembram o odor de "flores". ${ }^{17}$ Os alcoóis superiores não são importantes apenas devido aos seus odores característicos, mas também pela ação solvente sobre outras substâncias aromáticas, interferindo nos seus coeficientes de atividade e, dessa forma, nos seus limiares de odor. ${ }^{21}$

A quantidade de alcoóis superiores em aguardentes de cana brasileiras foi monitorada por CG/DIC. ${ }^{22}$ As amostras mostraram um teor total de alcoóis superior a $262 \mathrm{mg}$ por $100 \mathrm{~mL}$ de álcool anidro. Mais de uma dezena de alcoóis superiores foi quantificada, sendo os

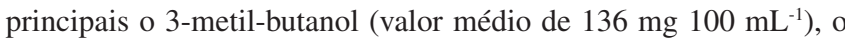

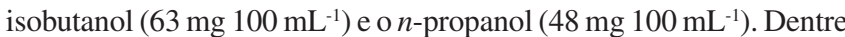
os minoritários se destacaram o hexadecanol $\left(6,1 \mathrm{mg} 100 \mathrm{~mL}^{-1}\right)$ e o álcool cinâmico $\left(6,9 \mathrm{mg} 100 \mathrm{~mL}^{-1}\right)$. O teor médio de metanol foi de $5,7 \mathrm{mg} 100 \mathrm{~mL}^{-1}$ de álcool anidro, bem abaixo do máximo permitido pela legislação. ${ }^{22}$ Em outro estudo, ${ }^{16}$ realizado com cachaças e suas misturas produzidas no sul de Minas Gerais, os alcoóis superiores propanol, butanol, 2-metilpropanol e 3-metilpentanol-1 também foram identificados e quantificados por CG/DIC. Nenhuma das amostras apresentou concentração de alcoóis superiores maior do que a permitida pela legislação (360 mg $100 \mathrm{~mL}^{-1}$ de álcool anidro). ${ }^{1}$ A baixa concentração desses alcoóis superiores foi relacionada com os cuidados no corte da cana, assim como com o tempo de espera para a moagem e fermentação. Quanto ao teor de etanol, somente 2 das 21 cachaças analisadas apresentaram valores abaixo do permitido pela legislação. O metanol não foi detectado ou estava presente nessas amostras em quantidades bastante reduzidas. ${ }^{16}$ Em 2008, 60 amostras de cachaça comercializadas na cidade de São Paulo foram avaliadas quanto ao teor de etanol e de componentes secundários. ${ }^{23}$ $\mathrm{O}$ teor de etanol dessas amostras variou de 34,7 a 46,9\% e em 10 amostras (17\%) a graduação alcoólica foi inferior a 38,0\%. Sete dessas amostras (12,0\%) apresentaram teores de alcoóis superiores maiores do que o limite máximo previsto na legislação. ${ }^{23}$

\section{Aldeídos}

Os aldeídos têm grande influência sobre o aroma e sabor das bebidas alcoólicas. Além disso, vários desses compostos (por exemplo, acetaldeído, furfural e HMF) são considerados tóxicos para os seres humanos, sendo associados aos efeitos desagradáveis do consumo excessivo de bebidas alcoólicas (sintomas de intoxicação e "ressaca"). ${ }^{16}$ Dentre estes sintomas podem-se destacar náusea, vômitos, agitação, transpiração, confusão e dores de cabeça. ${ }^{17}$ Dessa forma, um conteúdo reduzido de aldeídos nas aguardentes é frequentemente relacionado a bebidas de qualidade superior. Acredita-se, por exemplo, que cachaças ricas em acetaldeído sejam originárias de processos de destilação que não separam adequadamente a fração "cabeça" da bebida. ${ }^{16}$ Vários aldeídos já foram identificados como componentes das aguardentes de cana: formaldeído, acetaldeído, propenaldeído (acroleína), propionaldeído, butiraldeído, isovaleraldeído, $n$-valeraldeído, benzaldeído, furfural e HMF. ${ }^{9,16,17,24} \mathrm{O}$ formaldeído, acetaldeído e a acroleína merecem destaque tanto no que diz respeito aos supracitados efeitos tóxicos associados à classe dos aldeídos, quanto a sua influência sobre o aroma da bebida. ${ }^{17,25,26}$ Em termos de aroma, o formaldeído apresenta um limiar de odor de $830 \mu \mathrm{g} \mathrm{L} \mathrm{L}^{-1}$ no ar, sendo associado a um odor "pungente" e "sufocante"; o acetaldeído, um limiar de odor de $10 \mu \mathrm{g} \mathrm{L}^{-1}$ em água e de $50 \mu \mathrm{g} \mathrm{L}^{-1}$ no ar, com odor "pungente" quando concentrado e nota de "fruta" quando diluído; a acroleína possui um limite de detecção de $160 \mu \mathrm{g} \mathrm{L} \mathrm{L}^{-1}$ no ar, com odor desagradável de "ranço". ${ }^{26}$

Considerando que alguns estudos indicaram que as concentrações médias de formaldeído, acetaldeído e acroleína em amostras de aguardente eram de 0,$44 ; 43$ e 1,2 $\mathrm{mg} \mathrm{L}^{-1}$, respectivamente, pode-se concluir que esses aldeídos de menor massa molecular (MM) realmente podem ter participação importante no aroma dessas bebidas, já que alguns estão presentes em concentrações superiores aos seus limites de detecção pelo olfato humano. ${ }^{13,24}$ Em geral, aldeídos com até oito átomos de carbono, tais como acetaldeído, formaldeído, acroleína, benzaldeído e furfural, apresentam odores penetrantes, geralmente enjoativos, que são considerados indesejáveis para as aguardentes de cana. ${ }^{17}$ Destes aldeídos, o principal associado à fermentação alcoólica é o acetaldeído e o seu teor pode ser minimizado evitando-se a aeração no final da fermentação. ${ }^{27}$ Por outro lado, aldeídos maiores da série $\mathrm{C}_{8}-\mathrm{C}_{11}$ estão amplamente presentes na natureza e apresentam aroma agradável, conferindo nota odorífera de fruta cítrica ao aroma de vários produtos. ${ }^{17,28} \mathrm{O}$ furfural e o HMF são normalmente relacionados à queima do palhiço da cana-de-açúcar antes da colheita ou à presença de açúcares residuais durante o aquecimento do vinho no alambique. ${ }^{3}$

Uma série de carbonilas foi identificada na fração volátil de amostras brasileiras de aguardentes de cana na última década do século passado, dentre as quais uma dezena de aldeídos. Esses compostos foram separados pelo emprego do método de cromatografia líquida de alta eficiência (CLAE), após derivatização para a obtenção de compostos do tipo 2,4-dinitrofenilidrazonas. ${ }^{9,24} \mathrm{O}$ acetaldeído foi o aldeído majoritário das amostras, o que confirmou dados obtidos em estudo anterior. ${ }^{29}$ Em outro estudo, foi verificado que a aguardente produzida em alambique de cobre apresentou um maior conteúdo de aldeídos em relação ao produzido em coluna de aço. ${ }^{9}$ As maiores concentrações de aldeídos (com exceção do valeraldeído) nas amostras produzidas em alambique de cobre, quando comparadas às amostras destiladas em aço, foram atribuídas à conhecida reação de desidrogenação dos alcoóis. Depois que 21 amostras de cachaça do sul de Minas Gerais foram analisadas, concluiu-se que a concentração de aldeídos da maioria das amostras não se apresentava em excesso. Apenas duas dessas amostras excediam o limite máximo de aldeído exigido pela legislação brasileira. ${ }^{16}$ Já o estudo realizado com as cachaças comercializadas na cidade de São Paulo (60 amostras) mostrou que 31 amostras apresentavam concentrações de acetaldeído superiores ao limite máximo estabelecido pela legislação. ${ }^{23}$

\section{Cetonas}

Embora as cetonas estejam presentes em pequenas quantidades em bebidas alcoólicas, poderiam ter uma participação importante para o sabor e aroma dessas bebidas, ${ }^{30}$ incluindo as aguardentes de cana brasileiras. A 2,3-butanodiona, por exemplo, apresenta aroma semelhante à "manteiga". ${ }^{10}$ Em geral, as cetonas não são consideradas nocivas. Entretanto, a inalação prolongada desses compostos pode causar irritação das membranas mucosas, dores de cabeça, confusão, efeitos narcóticos e, também, pode levar a uma situação de coma. ${ }^{9}$ Alguns estudos desenvolvidos com o auxílio da CLAE 
após derivatização de cetonas para obtenção de compostos do tipo 2,4-dinitrofenilidrazonas foram desenvolvidos em aguardentes de cana brasileiras. ${ }^{9}$ Em um deles, foram separados 4 compostos dessa classe. A 2,3-butanodiona (valor médio de 4,3 $\mathrm{mg} \mathrm{L}^{-1}$ ) foi a cetona majoritária, seguida da acetona $\left(3,3 \mathrm{mg} \mathrm{L}^{-1}\right)$, da acetofenona $(1,2$ $\left.\mathrm{mg} \mathrm{L}^{-1}\right)$ e da ciclopentanona $\left(1,1 \mathrm{mg} \mathrm{L}^{-1}\right)$. Em outro, observou-se que o teor médio de acetona não variou de forma estatisticamente significativa entre a aguardente de cana produzida em alambique de cobre e a produzida em coluna de aço. ${ }^{9}$

\section{Ácidos orgânicos}

Quanto menor for a acidez da aguardente de cana, melhor será sua aceitação por parte dos consumidores. Dessa forma, o ácido acético é um composto importantíssimo para a qualidade das aguardentes de cana, uma vez que é o ácido majoritário encontrado nesse tipo de bebida, com concentração variando de 90 a $93 \%$ do conteúdo total de ácidos. ${ }^{17,31}$ Esse ácido tem grande influência sobre o sabor e aroma desse tipo de bebida, sendo relacionado a um odor penetrante e irritante, mais comumente descrito como odor de vinagre. ${ }^{10}$ Outros ácidos presentes em concentrações bem mais reduzidas do que o ácido acético também apresentam odores bem característicos. O ácido isovalérico (2-metil-butanoico), por exemplo, apresenta um odor "semelhante ao que é liberado por pés suados e abafados (chulé)", enquanto o ácido hexanoico (ácido cáprico) é responsável por um odor "pungente desagradável que lembra queijo". ${ }^{10}$ A maioria dos ácidos alifáticos de cadeia curta possui limiares de odor em solução aquosa variando de 4 a 8 ppm. ${ }^{10}$ Outros ácidos maiores (p. ex.: ácido decanoico ou cáprico) também apresentam aromas desagradáveis associados, por exemplo, a notas de "ranço", apesar de apresentarem limiares de odor mais elevados. ${ }^{32}$ Não são atribuídas propriedades tóxicas aos ácidos livres encontrados nas aguardentes de cana. ${ }^{31}$

A cromatografia gasosa acoplada ao detector de ionização em chama (CG/DIC) foi usada para análise de ácidos orgânicos em amostras de aguardente de cana brasileira. ${ }^{24,33}$ Foram usados a extração em fase sólida, com cartucho $\mathrm{C}_{18}$, para pré-concentração das amostras e o diclorometano para eluição do analito, não havendo uso de quaisquer métodos de derivatização e de extração líquido-líquido, o que reduziu consideravelmente o tempo de análise. O método de extração em fase sólida apresentou reprodutibilidade e exatidão satisfatórias para os ácidos graxos de cadeia média e longa $\left(\mathrm{C}_{7}-\mathrm{C}_{16}\right)$, porém mostrou uma recuperação baixa para os ácidos de cadeia curta $\left(\mathrm{C}_{3}-\mathrm{C}_{6}\right)$. A concentração desses últimos foi estimada usando-se um fator de recuperação experimental obtido para cada um deles. O ácido acético, que foi dosado na amostra sem extração em fase sólida, foi o componente majoritário (valor médio de 99,2 mg $100 \mathrm{~mL}^{-1}$ ). Outros 13 ácidos minoritários foram quantificados: propanoico (valor médio de 0,17 mg $\left.100 \mathrm{~mL}^{-1}\right)$, isobutanoico $\left(0,08 \mathrm{mg} 100 \mathrm{~mL}^{-1}\right)$, butanoico $(0,01 \mathrm{mg}$ $\left.100 \mathrm{~mL}^{-1}\right)$, isopentanoico $\left(0,12 \mathrm{mg} 100 \mathrm{~mL}^{-1}\right)$, pentanoico $(0,03 \mathrm{mg}$ $\left.100 \mathrm{~mL}^{-1}\right)$, isoexanoico $\left(0,03 \mathrm{mg} 100 \mathrm{~mL}^{-1}\right)$, hexanoico $(0,21 \mathrm{mg} 100$ $\left.\mathrm{mL}^{-1}\right)$, heptanoico $\left(0,03 \mathrm{mg} 100 \mathrm{~mL}^{-1}\right)$, octanoico $\left(1,3 \mathrm{mg} 100 \mathrm{~mL}^{-1}\right)$, decanoico $\left(1,6 \mathrm{mg} 100 \mathrm{~mL}^{-1}\right)$, dodecanoico $\left(0,60 \mathrm{mg} 100 \mathrm{~mL}^{-1}\right)$, tetradecanoico $\left(0,37 \mathrm{mg} 100 \mathrm{~mL}^{-1}\right)$ e hexadecanoico $\left(0,32 \mathrm{mg} 100 \mathrm{~mL}^{-1}\right)$. Os ácidos, com anel aromático, fenilacético, fenilpropanoico e benzoico não foram identificados (ordem de grandeza de micrograma). Cerca de $20 \%$ das amostras comercializadas no mercado interno excederam o valor máximo permitido pela legislação. ${ }^{33}$ Em outro estudo, foi usada a técnica de CLAE com detector de fluorescência para a análise de 17 ácidos graxos em aguardentes de cana, ${ }^{34}$ sendo que as amostras também foram pré-concentradas em cartucho $\mathrm{C}_{18} \mathrm{e}$, em seguida, eluídas com diclorometano. O eluato então foi derivatizado com 9-antrildiazometano, formando os respectivos ésteres de antri-metila dos ácidos graxos. Esse método ${ }^{34}$ é vantajoso em relação ao anterior ${ }^{33}$ porque é muito mais seletivo e sensível, permitindo um limite de detecção na faixa de 5-15 fmol. Essa maior sensibilidade permitiu a dosagem do ácido cis,cis-9,12-octadecadienoico (linoleico) e de uma mistura dos ácidos octadecanoico e cis-9-octadecenoico (oléico). Aliás, a coeluição desses 2 ácidos foi a principal limitação do método. Em outro estudo usando $\mathrm{CG} / \mathrm{DIC},{ }^{35}$ foi mostrado que o tipo de aparelho de destilação influencia na composição quantitativa dos ácidos orgânicos da bebida. Concluiuse que o corte do destilado em cabeça, coração e cauda e, portanto, a distinção dessas frações necessita de uma melhor padronização. ${ }^{35}$

\section{Ésteres}

Ao lado dos alcoóis superiores, os ésteres são, quantitativa e qualitativamente, um dos maiores grupos de compostos da fração volátil das bebidas alcoólicas. ${ }^{12}$ Os ésteres etílicos de ácidos graxos e acetatos são considerados os mais importantes em bebidas alcoólicas, em função de suas concentrações serem relativamente elevadas, de suas características de aroma serem normalmente agradáveis e de seus limiares de odor serem relativamente baixos. ${ }^{12}$ Os ésteres mais abundantes nas aguardentes de cana tendem a ser aqueles derivados dos ácidos (p. ex.: ácido acético) e alcoóis (p. ex.: etanol) mais abundantes. ${ }^{12}$

A fração volátil de amostras de aguardente não envelhecida foi analisada através da CG/EM. ${ }^{12}$ Esse autor usou uma armadilha do adsorvente Tenax - TA para reter os compostos voláteis da fração headspace. Essa fração corresponde à fase gasosa (primeira a ser percebida pelo olfato) imediatamente acima da matriz. Dentre os compostos majoritários encontrados nas aguardentes de cana analisadas estavam os ésteres decanoato de etila, hexanoato de etila, octanoato de etila, acetato de 3-metilbutila e dodecanoato de etila. Os odores específicos desses ésteres majoritários foram descritos como "uva", "casca de maçã", "frutado", "banana" e "folha de planta", respectivamente. ${ }^{12}$ Desse grupo, os ésteres com estruturas carbônicas mais leves, como o acetato de 3-metilbutila, têm geralmente maior volatilidade e menor valor de limiar de odor, sendo considerados importantes para o aroma global da bebida. O acetato de 3-metilbutila, por exemplo, apresenta limiar de odor em água de 19 ppb. $^{12}$ Por outro lado, aqueles ésteres com estruturas carbônicas maiores, como é o caso do dodecanoato de etila, são menos voláteis e apresentam maiores limiares de odor, sendo sua contribuição sensorial teoricamente limitada mais à textura (oleosidade) e ao palato do que ao aroma. ${ }^{12}$ Nesse mesmo estudo da fração headspace de amostras de aguardente de cana, os ésteres minoritários mostraram-se potencialmente importantes para o aroma, pois apresentaram valores baixos para seus limiares de odor estabelecidos em água. Estes ésteres foram identificados como propanoato de etila (limiar de odor $=5 \mathrm{ppb})$, butanoato de etila $(1 \mathrm{ppb})$, pentanoato de etila (5 ppb), acetato de hexila ( $2 \mathrm{ppb}$ ) e heptanoato de etila (2 ppb). Os odores do propanoato de etila, butanoato de etila, pentanoato de etila e acetato de hexila têm sido descritos individualmente como "frutado", "maçã", "fermento" e "frutado", respectivamente. ${ }^{12}$ Os perfis qualitativo e quantitativo de ésteres em amostras de aguardente de cana brasileira também foram investigados através da CG/DIC ${ }^{22}$ e $\mathrm{CG} / \mathrm{EM}^{36}$ por outros pesquisadores. Aproximadamente $95 \%$ das amostras apresentaram um conteúdo total de ésteres dentro do limite estabelecido pela legislação. O acetato de etila (limiar de odor em água de $1.000 \mathrm{ppb})^{12}$ foi o éster majoritário (valor médio de $44 \mathrm{mg}$ $\left.100 \mathrm{~mL}^{-1}\right)$, seguido pelo lactato de etila $\left(25 \mathrm{mg} 100 \mathrm{~mL}^{-1}\right) .{ }^{36}$ Juntos os 2 ésteres representaram mais de $95 \%$ da quantidade de ésteres totais identificados nessas amostras. Outros sete ésteres menos abundantes foram quantificados: butanoato de etila (valor médio de $0,63 \mathrm{mg} 100$ $\left.\mathrm{mL}^{-1}\right)$, hexanoato de etila $\left(0,20 \mathrm{mg} 100 \mathrm{~mL}^{-1}\right)$, octanoato de etila $(0,66$ $\left.\mathrm{mg} 100 \mathrm{~mL}^{-1}\right)$, nonanoato de etila $\left(0,07 \mathrm{mg} 100 \mathrm{~mL}^{-1}\right)$, decanoato de etila (1,4 mg $\left.100 \mathrm{~mL}^{-1}\right)$, octanoato de 3-metil-1-butila (octanoato de iso-

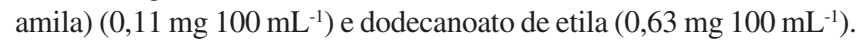


A ocorrência de lactato de etila está associada à contaminação por Lactobacillus spp. que é responsável pela fermentação láctica. As fontes mais prováveis de contaminação seriam as matérias-primas (p.ex.: cana, levedura, água) ou o próprio aparato de destilação. Essa fermentação concorrente não afeta o rendimento de etanol. ${ }^{36}$ É possível que o lactato de etila tenha alguma contribuição positiva para o sabor e aroma das bebidas alcoólicas. ${ }^{37}$ Há a necessidade de se realizar estudos olfatométricos para se verificar a real participação do lactato de etila no aroma da aguardente de cana brasileira. As notas odoríferas de fruta percebidas no aroma das bebidas alcoólicas são, geralmente, associadas à presença de ésteres de ácidos graxos de MM baixa. ${ }^{38,39} \mathrm{De}$ fato, uma nota odorífera semelhante à de "maçã", identificada no aroma de tequila, foi associada à presença de hexanoato de etila. ${ }^{30}$ Também foi estudado o efeito do tipo de alambique na composição de ésteres em amostras de aguardente. ${ }^{36}$ As bebidas produzidas em alambique híbrido de cobre e aço inox apresentaram um maior conteúdo total de ésteres $\left(73 \mathrm{mg} 100 \mathrm{~mL}^{-1}\right)$ quando comparadas àquelas produzidas em alambique de cobre (54 mg $100 \mathrm{~mL}^{-1}$ ) ou em coluna de ácido inox (20 $\mathrm{mg} 100 \mathrm{~mL}^{-1}$ ). Alguns fatores poderiam contribuir para essas diferenças: a temperatura da destilação, o número de pratos teóricos em cada aparato de destilação e a atividade catalítica do metal na superfície do destilador que, em contato com a fase de vapor, aceleraria as reações de esterificação. ${ }^{9,36}$ As aguardentes obtidas de alambique têm um conteúdo elevado de ésteres com MM baixa que apresentam um coeficiente de partição alto. Dessa forma, essas bebidas apresentam notas odoríferas de "frutas" mais intensas. Já as bebidas produzidas em coluna de aço possuem um teor mais alto de ésteres de cadeia longa, provavelmente devido ao aumento do ponto de ebulição e do coeficiente de atividade dos ésteres, este último dependente da concentração de etanol e do comprimento da cadeia dos ésteres. ${ }^{36}$ Alguns ésteres minoritários também foram identificados e quantificados através da técnica de CG/DIC: pentanoato de isoamila (valor médio de $0,01 \mathrm{mg} 100 \mathrm{~mL}^{-1}$ ), propionato de amila, propionato de metila, butanoato de propila $(0,02$ $\mathrm{mg} 100 \mathrm{~mL}^{-1}$ para cada um), heptanoato de etila $\left(0,05 \mathrm{mg} 100 \mathrm{~mL}^{-1}\right)$ e benzoato de etila $\left(0,46 \mathrm{mg} 100 \mathrm{~mL}^{-1}\right) .^{22}$ Esses autores observaram que o conteúdo total de ésteres nas aguardentes de cana (23 mg 100 $\mathrm{mL}^{-1}$ ), expresso em acetato de etila, foi menor do que o encontrado em outras bebidas fermento-destiladas, como o rum $\left(70 \mathrm{mg} 100 \mathrm{~mL}^{-1}\right)$ e o uísque (74 mg $\left.100 \mathrm{~mL}^{-1}\right){ }^{22}$

\section{Acetais}

A classe de compostos voláteis conhecida como acetais também foi detectada no headspace de amostras de aguardente de cana comercializadas na cidade de João Pessoa, PB. ${ }^{12}$ Como mencionado anteriormente, estes compostos são formados através da reação entre aldeídos e alcoóis, fazendo com que o odor pungente dos aldeídos seja reduzido à medida que essas reações se desenvolvem. ${ }^{12}$ Como o aldeído e o álcool majoritários nas bebidas alcoólicas são o acetaldeído e o etanol, não foi surpresa que o 1,1-dietóxi-etano (acetaldeído dietil acetal) tenha sido detectado em concentrações relativamente elevadas no headspace das aguardentes estudadas. Esse composto tem limiar de odor em água de 40 ppb e odor "refrescante", "frutado" e "verde". ${ }^{12}$ Dessa forma, o 1,1-dietóxi-etano pode contribuir para o aroma final dessas bebidas de forma direta, pelas suas supracitadas características de aroma ou, de forma indireta, pela redução dos níveis de acetaldeído. Além desse acetal, o pesquisador também identificou tentativamente o 1-etóxi-1-pentóxi-etano (acetaldeído etil pentil acetal). ${ }^{12}$

\section{Compostos sulfurados}

As aguardentes de cana brasileiras podem apresentar um defeito sensorial quando destiladas em alambique de aço inox. Este defeito tem sido atribuído à ausência de cobre e foi relacionado à presença de compostos sulfurados. ${ }^{40}$ Esses compostos, particularmente o sulfeto de dimetila (DMS), geralmente são responsáveis por aroma desagradável (odor de sulfetos) em alimentos e bebidas. ${ }^{9,41}$ Através da CG/EM foi possível confirmar que o defeito sensorial presente nas aguardentes destiladas na ausência de cobre foi devido ao DMS..$^{40} \mathrm{O}$ teor de DMS nas amostras destiladas em alambiques de aço $(250 \mathrm{mg}$ $\left.\mathrm{L}^{-1}\right)$ é superior ao das amostras destiladas em alambiques de cobre (150 $\left.\mathrm{mg} \mathrm{L}^{-1}\right)$. Também foi constatado que amostras destiladas em alambiques de cobre contêm cerca de 4 vezes mais sulfato $(17 \mathrm{mg}$ $\left.\mathrm{L}^{-1}\right)$ do que as destiladas em alambiques de aço $\left(4 \mathrm{mg} \mathrm{L}^{-1}\right) .{ }^{9} \mathrm{O} \mathrm{Cu}^{2+}$ parece agir de forma a catalisar a conversão de sulfetos a sulfatos, reduzindo, portanto, o odor desagradável típico dos sulfetos. ${ }^{24}$ Foi investigada a origem dos compostos sulfurados presentes nas aguardentes de cana brasileiras. ${ }^{14}$ Elas foram separadas em 2 grupos: no primeiro, o caldo fermentado foi submetido à centrifugação antes da destilação, enquanto no outro o caldo não foi centrifugado. Os teores de enxofre foram significativamente maiores $(p \leq 0,05)$ nas amostras não centrifugadas. Esses resultados são indicativos de que há degradação de aminoácidos sulfurados (metionina e cisteína) de proteínas da levedura Saccharomyces cerevisiae durante o processo de destilação, gerando compostos sulfurados voláteis.

\section{Influência do envelhecimento em barris de madeira sobre a composição da fração volátil das aguardentes de cana}

Em estudo recente, ${ }^{42}$ foram observadas alterações da composição química da aguardente envelhecida em barris de carvalho por 390 dias. Houve um aumento do teor total de acidez volátil, furfural, ésteres, aldeídos, enquanto que as quantidades de metanol, etanol e $n$-propanol não se alteraram. O teor de isobutanol cresceu em $12 \%$, enquanto o teor de 3-metil-butanol e seus isômeros aumentou em 18\%. ${ }^{42}$ Outro estudo para avaliar os efeitos da madeira sobre a qualidade e composição química da aguardente de cana envelhecida em barris de carvalho também foi conduzido em 2008.$^{27}$ As amostragens para a realização das análises foram desenvolvidas a cada 3 meses, durante 3 anos. As aguardentes armazenadas nesses barris apresentaram diferenças significativas em relação às épocas de amostragem para todos os parâmetros analisados (teor alcoólico, de polifenóis, acetaldeído, acetato de etila, metanol, álcool $n$-butílico, $n$-propílico, isobutílico, isoamílico, acidez e cobre), com exceção do teor do álcool $n$-butílico. O mesmo não aconteceu com as amostras armazenadas em recipiente de vidro, com exceção do teor de acetato de etila. Concluiu-se que os recipientes utilizados e o tempo de armazenamento interferem nas características químicas e na qualidade da aguardente de cana. ${ }^{27}$

Foi publicado um estudo comparando o perfil de compostos voláteis das amostras de aguardente de cana brasileira não envelhecida (fração coração) com aquelas envelhecidas em barris de bálsamo (Myroxylon sp) (durante um período de 1 e 2 anos) e carvalho (Quercus sp) (durante um período de 1, 2 e 5 anos). ${ }^{43}$ Todas as amostras estavam em consonância com a legislação. Foi usada a cromatografia de adsorção com adsorvente Porapak para concentrar a fração volátil que foi dessorvida com acetona. Em seguida, o extrato em acetona foi concentrado em rotaevaporador e submetido a uma análise cromatográfica. As técnicas de CG/DIC, CG/EM, CG/olfatometria (CG/O) e ADEA (análise de diluição do extrato de aroma) foram usadas para identificar compostos voláteis, suas notas odoríferas e seu impacto sobre o aroma das bebidas. Não foram identificados quaisquer aldeídos nas amostras de aguardente não envelhecidas e envelhecidas em barris de bálsamo e carvalho, devido à coeluição da acetona com essas carbonilas durante a análise por CG. ${ }^{43}$ No que diz respeito às cetonas, duas foram identificadas: a 4-metil-3-penten-2-ona (valor médio de $0,08 \mathrm{mg} 100 \mathrm{~mL}^{-1}$ ) e a 3-hidróxi-2-butanona 
(0,03 mg $\left.100 \mathrm{~mL}^{-1}\right)$. Ambas as cetonas foram compostos típicos da fração volátil de aguardentes envelhecidas em barril de carvalho. Com o uso da CG-O, foi possível identificar duas notas odoríferas associadas à 3-hidróxi-2-butanona: uma "doce" e outra de "madeira". Porém, o uso da ADEA indicou que a 3-hidróxi-2-butanona não é um composto de impacto direto para o aroma das aguardentes de cana. O odor da 3-hidróxi-2-butanona em amostras de tequila tem sido associado a uma nota odorífera de "manteiga". ${ }^{30}$

Foi possível identificar 8 ácidos graxos saturados nas amostras de aguardente não envelhecida e envelhecida em barris de bálsamo e carvalho. ${ }^{43} \mathrm{O}$ ácido acético foi o composto majoritário, com a acidez volátil apresentando valores médios de 0,06-0,12 g $100 \mathrm{~mL}^{-1}$ de álcool anidro. Em relação aos ácidos da série $\left(\mathrm{C}_{7}-\mathrm{C}_{16}\right)$, o decanoico (valor médio de $\left.0,44 \mathrm{mg} 100 \mathrm{~mL}^{-1}\right)$ e o dodecanoico $\left(0,45 \mathrm{mg} 100 \mathrm{~mL}^{-1}\right)$ foram os majoritários, contudo, o ácido dodecanoico não foi identificado nas amostras envelhecidas em barris de carvalho, possivelmente devido à coeluição com um interferente. Nenhum ácido graxo foi considerado odorante de impacto para o aroma das amostras de aguardente de cana (envelhecida ou não).$^{43}$ As aguardentes envelhecidas em barris de carvalho apresentaram concentrações maiores dos ésteres decanoato de etila (valor médio de 1,51-1,87 mg $100 \mathrm{~mL}^{-1}$ ) e dodecanoato de etila $\left(0,93-1,25 \mathrm{mg} 100 \mathrm{~mL}^{-1}\right)$, quando comparadas às amostras não envelhecidas $(0,93) \mathrm{e}(0,61)$ e envelhecidas em barris de bálsamo $(0,85-0,95)$ e $(0,45-0,47)$, respectivamente. O conteúdo de octanoato de etila (valor médio de $1,24 \mathrm{mg} \mathrm{mL}^{-1}$ ) foi maior nas amostras envelhecidas em barris de carvalho por 5 anos em comparação a todas as outras. Já o 9-octadecenoato de etila foi identificado somente nas amostras envelhecidas em barris de carvalho. ${ }^{43}$ Os ésteres $\mathrm{C}_{8}, \mathrm{C}_{10}$ e $\mathrm{C}_{12}$ são considerados compostos importantes no aroma de outras bebidas destiladas como, por exemplo, o rum. ${ }^{44} \mathrm{O}$ lactato de etila foi achado em pequenas quantidades em todas as amostras, apresentando valores médios de $0,11-0,33 \mathrm{mg} \mathrm{mL}^{-1}$. Isto poderia, a princípio, indicar que a fermentação láctica foi um evento de menor importância durante todas as etapas de produção das amostras de aguardente de cana. $\mathrm{O}$ dodecanato de etila, com notas "doce" e "semelhante à madeira" e o dodecanoato de 2-metil-1-butila, com nota "pungente", somente foram percebidos nas amostras não envelhecidas e envelhecidas em bálsamo. Já o propanoato de feniletila, com nota "semelhante à madeira", o tridecanoato de etila, com notas de "mato" e "doce", e o hexanoato de etila, com nota de "fruta", só foram percebidos nas amostras não envelhecidas e envelhecidas em carvalho. Com base nos dados preliminares obtidos com a técnica de ADEA, o octanoato de etila, com nota de "azeitona" ( $\left.F D=2^{1}-2^{2}\right)$, foi o único éster apontado como odorante importante para a aguardente de cana brasileira. ${ }^{43}$

Em relação aos alcoóis identificados nas amostras de aguardente envelhecida e não envelhecida, houve uma predominância do 3-metil-butanol e do isobutanol. ${ }^{43}$ Entretanto, o conteúdo de 3-metil-butanol e de isobutanol foi cerca de 20-30\% maior nas amostras de aguardente não envelhecida em comparação àquelas envelhecidas. ${ }^{43}$ As aguardentes não envelhecidas apresentaram um conteúdo menor de 2-feniletanol (valor médio de $0,24 \mathrm{mg} \mathrm{mL}^{-1}$ ) quando comparadas às amostras envelhecidas $(0,35-0,48)$. Os dados iniciais obtidos através da CG/O e ADEA indicaram que o 3-metil-butanol, com notas "pungente" e de "solvente" (FD = 2 $1-2^{2}$ ), e o 2-feniletanol, com notas de "mato" e de "fruta" $\left(\mathrm{FD}=2^{1}-2^{2}\right)$, foram odorantes importantes para o aroma de todas as aguardentes envelhecidas. Somente o 3-metil-butanol foi considerado um odorante relevante para o aroma das amostras não envelhecidas. ${ }^{43} \mathrm{O}$ 3-metil-butanol, com notas "doce" e de "óleo fúsel", e o 2-feniletanol, com nota "floral", também foram apontados como odorantes potentes para o aroma da tequila. ${ }^{30}$

O perfil de compostos fenólicos em aguardentes de cana é usado como marcador de envelhecimento e autenticidade da bebida. Analisaram-se os compostos fenólicos em aguardentes envelhecidas por 6 meses em barris de diversas madeiras brasileiras e de carvalho. ${ }^{15}$ Foi descrito que cada tipo de madeira introduziu compostos fenólicos específicos na bebida como, por exemplo, ácidos elágico e vanílico no carvalho, ácido vanílico e sinapaldeído na amburana, vanilina e ácido elágico no bálsamo, ácido gálico no jequitibá, coniferaldeído no jatobá e ácidos siríngico e vanílico e coniferaldeído no ipê.

Em outro trabalho mais complexo, o uso de análise quimiométrica do perfil quantitativo de 14 compostos fenólicos (ácidos: elágico, gálico, vanílico e siríngico; aldeídos: siringaldeído, sinapaldeído e coniferaldeído; vanilina, quercetina, trans-resveratrol, catequina, epicatequina, eugenol e miricetina) e duas cumarinas (escopoletina e cumarina) permitiu caracterizar e diferenciar 6 grupos de extratos de madeira: carvalho; jatobá; Myrocarpus frondosus (cabreúva-parda); Arachis hypogaea L. (amendoim); Ocotea pretiosa (canela-sassafrás) e Caryocar brasiliense (pequi).$^{45} \mathrm{~A}$ presença de cumarinas (especialmente escopoletina) é considerada como um fator de reconhecimento do envelhecimento da bebida em barris de carvalho. ${ }^{46}$ Os compostos fenólicos também provocam alterações sensoriais importantes. ${ }^{47}$ Foi descrito em um estudo de análise descritiva quantitativa da aguardente envelhecida em tonel de carvalho, comparada com uma aguardente recém-destilada, que o aumento do tempo de envelhecimento da bebida aumenta a coloração amarela, os aromas de madeira e baunilha, a doçura inicial e residual, o sabor de madeira inicial e residual, a adstringência e a acidez e, diminui o aroma alcoólico, sabor alcoólico inicial e residual e a agressividade da mesma. ${ }^{48}$ Foi possível associar tais resultados com o aumento da aceitação de bebidas envelhecidas. ${ }^{48}$ Além do tipo de madeira utilizada para o envelhecimento, a idade e o número de vezes que os tonéis são usados também influenciam na composição dos compostos voláteis, visto que estes fatores alteram a extração e oxidação dos aldeídos e ácidos fenólicos (Tabela 2). ${ }^{49}$

\section{CONCLUSÃO}

A fração volátil das aguardentes de cana tem importante papel sobre a qualidade e aceitação desse tipo de bebida. As formas como se conduz a colheita da cana-de-açúcar, a fermentação, a destilação e o envelhecimento da aguardente são determinantes da composição qualitativa e quantitativa da fração volátil dessas bebidas alcoólicas. Os materiais usados nesses processos também têm grande influência sobre a composição química desse tipo de matriz. Apesar de serem os principais componentes das aguardentes de cana, o etanol e a água não merecem destaque no que diz respeito a sua contribuição para o aroma dessas bebidas. Por outro lado, há vários compostos secundários encontrados nessas bebidas destiladas que têm grande participação no aroma e sabor das mesmas. Desses compostos secundários, os alcoóis, ácidos e ésteres formam os grupos mais abundantes, enquanto aldeídos, cetonas, acetais, compostos sulfurados e fenólicos constituem os grupos minoritários. Os estudos desenvolvidos nessa área mostram que o acetato de etila e o lactato de etila são os ésteres majoritários. Aldeídos como o acetaldeído, o propenaldeído e o furfural podem contribuir negativamente para o sabor dessas bebidas alcoólicas. A 2,3-butanodiona e o ácido acético são a cetona e o ácido majoritários dessas bebidas destiladas. O sulfeto de dimetila e o $n$-propanol são prejudiciais para o sabor e aroma das mesmas. Por outro lado, acetais como o 1,1-dietóxi-etano podem contribuir positivamente para o aroma das aguardentes, em função de suas características sensoriais e do efeito que sua produção tem sobre a diminuição dos níveis de certos aldeídos. As técnicas de CG/O/ADEA indicaram que o octanoato de etila, o 2-feniletanol e o 3-metil-butanol são odorantes importantes para o aroma da bebida envelhecida. Os compostos fenólicos (p. ex.: vanilina e eugenol) também provocam alterações sensoriais importantes nas aguardentes envelhecidas e podem ser usados como marcadores do envelhecimento e da autenticidade dessas bebidas. 
Tabela 2. Perfil de alguns dos principais compostos voláteis influenciadores do aroma de cachaças e aguardentes de cana brasileiras

\begin{tabular}{|c|c|c|c|c|c|}
\hline Composto & P.E. $\left({ }^{\circ} \mathrm{C}\right)$ & Limiar de odor & Descrição sensorial & Concentração & Ref. \\
\hline Etanol & $78^{50}$ & 100.000 ppb (em água) ${ }^{12}$ & Álcool, doce ${ }^{51}$ & $38-54 \%(\mathrm{v} / \mathrm{v})^{1}$ & $1,12,50,51$ \\
\hline$n$-Propanol & $97^{50}$ & $0,094 \mathrm{ppm}$ (em fase gasosa) ${ }^{52}$ & Álcool, pungente ${ }^{51}$ & $\left(46 \mathrm{mg} 100 \mathrm{~mL}^{-1}\right)^{22}$ & $22,50,51,52$ \\
\hline n-Butanol & $117,6^{50}$ & 500 ppb (em água) $)^{53}$ & Vinho $^{51}$ & $\left(3 \mathrm{mg} 100 \mathrm{~mL}^{-1}\right)^{1}$ & $1,50,51,53$ \\
\hline 2-metilpropanol-1 & $108^{54}$ & $\begin{array}{c}40.000 \mu \mathrm{L} / \mathrm{L} \\
(\text { em água/etanol, } 90+10, \mathrm{~m} / \mathrm{m})^{55}\end{array}$ & $\begin{array}{l}\text { Vinho, solvente, } \\
\text { amargo }^{51}\end{array}$ & $\left(63 \mathrm{mg} 100 \mathrm{~mL}^{-1}\right)^{22}$ & $22,51,54,55$ \\
\hline 2-metilbutanol-1 & $128^{54}$ & $1,7 \mathrm{ppb}(\mathrm{em} \text { fase gasosa })^{52}$ & Malte, vinho, cebola ${ }^{51}$ & $\left(0,13 \mathrm{mg} 100 \mathrm{~mL}^{-1}\right)^{22}$ & $22,51,52,54$ \\
\hline 3-metilbutanol-1 & $\begin{array}{l}109,5-110,5 \\
(742 \mathrm{~mm} \mathrm{Hg})^{54}\end{array}$ & 250 ppb (em água) $)^{53}$ & $\begin{array}{c}\text { Uísque, malte, al- } \\
\text { coólico, vínico, banana } \\
\text { e doce }{ }^{12}\end{array}$ & $136 \mathrm{mg} / 100 \mathrm{~mL}^{22}$ & $12,22,53,54$ \\
\hline 2-feniletanol & $219-221^{50}$ & $7,5 \mathrm{mg} \mathrm{L}^{-1}$ (em água) $)^{56}$ & Mate, fruta, floral ${ }^{43,30}$ & $\left(0,35-0,48 \mathrm{mg} \mathrm{mL}^{-1}\right)^{43}$ & $30,43,50,56$ \\
\hline Ácido acético & $118-119^{50}$ & $300 \mathrm{mg} \mathrm{L}^{-1}$ (modelo de vinho) $)^{56}$ & $\begin{array}{l}\text { Odor penetrante e irri- } \\
\text { tante, odor de vinagre }{ }^{10}\end{array}$ & $\left(57,5-50 \mathrm{mg} 100 \mathrm{~mL}^{-1}\right)^{1,33}$ & $1,10,33,50,56$ \\
\hline Acetato de etila & $76,5-77,5^{50}$ & $\begin{array}{c}7.500 \mu \mathrm{L} / \mathrm{L} \\
(\text { em água/etanol, } 90+10, \mathrm{~m} / \mathrm{m})^{55}\end{array}$ & $\begin{array}{l}\text { Odor frutal que se } \\
\text { torna desagradável e } \\
\text { semelhante a solvente } \\
\text { em conc. elevada }^{57}\end{array}$ & $\begin{array}{c}\left(44 \mathrm{mg} 100 \mathrm{~mL}^{-1}\right)^{36} \\
\left(5,4-200 \mathrm{mg} 100 \mathrm{~mL}^{-1}\right)^{58}\end{array}$ & $36,50,55,57,58$ \\
\hline Lactato de etila & $151^{50}$ & 14.000 ppb (em água) $)^{59}$ & Frutado $^{36}$ & $\left(25 \mathrm{mg} 100 \mathrm{~mL}^{-1}\right)^{36}$ & $36,50,59$ \\
\hline Octanoato de etila & $206-208^{50}$ & $\begin{array}{c}2 \mu \mathrm{g} / \mathrm{L} \\
(\text { em água/etanol, } 90+10, \mathrm{~m} / \mathrm{m})^{55}\end{array}$ & Frutado, abacaxi ${ }^{51}$ & $\begin{array}{l}\left(0,661 \mathrm{mg} 100 \mathrm{~mL}^{-1}\right)^{36} \\
\quad\left(1,24 \mathrm{mg} \mathrm{mL}^{-1}\right)^{43}\end{array}$ & $36,43,50,51,55$ \\
\hline Furfural & $54-56^{50}$ & 3000 ppb (em água) $)^{53}$ & Pão, amêndoa, doce ${ }^{51}$ & $\begin{array}{c}\left(0,014-0,0214 \mathrm{mg} 100 \mathrm{~mL}^{-1}\right)^{60} \\
\left(5,12 \mathrm{mg} \mathrm{L}^{-1}\right)^{24}\end{array}$ & $24,50,51,53,60$ \\
\hline 5-Hidroximetilfurfural & $114-116^{50}$ & $\mathrm{Nd}$ & $\mathrm{Nd}$ & $\begin{array}{c}\left(0,491-0,520 \mathrm{mg} 100 \mathrm{~mL}^{-1}\right)^{60} \\
\left(1,54 \mathrm{mg} \mathrm{L}^{-1}\right)^{24}\end{array}$ & $24,50,60$ \\
\hline Acetaldeído & $65-82^{50}$ & $\begin{array}{c}10 \mu \mathrm{L} / \mathrm{L}(\text { em água })^{26} \\
50 \mu \mathrm{L} / \mathrm{L}(\text { ar })^{26}\end{array}$ & $\begin{array}{l}\text { Pungente quando } \\
\text { concentrado e frutado } \\
\text { quando diluído }{ }^{26}\end{array}$ & $\left(43 \mathrm{mg} \mathrm{L}^{-1}\right)^{24}$ & $24,26,50$ \\
\hline Formaldeído & $97^{50}$ & $830 \mu \mathrm{L} / \mathrm{L}(\operatorname{ar})^{26}$ & Pungente, sufocante ${ }^{26}$ & $\left(0,44 \mathrm{mg} \mathrm{L}^{-1}\right)^{24}$ & $24,26,50$ \\
\hline Propenaldeído & $53^{50}$ & $160 \mu \mathrm{L} / \mathrm{L}(\mathrm{ar})^{26}$ & $\operatorname{Ranço}^{26}$ & $\left(1,25 \mathrm{mg} \mathrm{L}^{-1}\right)^{24}$ & $24,26,50$ \\
\hline 2,3-Butanodiona & $88^{50}$ & $10-20 \mathrm{ng} / \mathrm{L}(\operatorname{ar})^{61}$ & Manteiga $^{61}$ & $\left(4,3 \mathrm{mg} \mathrm{L}^{-1}\right)^{9}$ & $9,50,61$ \\
\hline 3-hidróxi-2-butanona & $148^{50}$ & 800 ppb (em água) $)^{59}$ & $\begin{array}{l}\text { Doce, madeira, man- } \\
\text { teiga }^{43,51}\end{array}$ & $\left(1597 \mu \mathrm{g} \mathrm{L}^{-1}\right)^{62}$ & $43,50,51,59,62$ \\
\hline 1,1-dietóxi-etano & $103^{50}$ & 40 ppb (em água) ${ }^{12}$ & $\begin{array}{c}\text { Refrescante, frutado e } \\
\text { verde }^{12}\end{array}$ & $(4.554 \mathrm{ng} / 40 \mathrm{~mL})^{12}$ & 12,50 \\
\hline Sulfeto de dimetila & $38^{50}$ & $0.33 \mathrm{ppb}$ (em água) $)^{53}$ & $\begin{array}{l}\text { Odor desagradável } \\
\text { típico de sulfetos }{ }^{63}\end{array}$ & $(2,13-3,78 \mathrm{ppm})^{63}$ & $50,53,63$ \\
\hline Eugenol & $254^{50}$ & 6 ppb (em água) $)^{53}$ & $\begin{array}{l}\text { Cravo-da-índia, dental, } \\
\text { mel }^{51,64}\end{array}$ & $\left(66 \mu \mathrm{g} \mathrm{L}^{-1}\right)^{62}$ & $50,51,53,62,64$ \\
\hline Vanilina & $170^{50}$ & $0,6-1,2 \mathrm{ng} \mathrm{L}^{-1}(\operatorname{ar})^{61}$ & Baunilha $^{51}$ & $\left(63 \mu \mathrm{g} \mathrm{L}^{-1}\right)^{62}$ & $50,51,61,62$ \\
\hline
\end{tabular}

P.E. = ponto de ebulição; $\mathrm{Nd}-$ não disponível.

\section{REFERÊNCIAS}

1. Brasil, Ministério da Agricultura Pecuária e Abastecimento; Instrução Normativa $\mathrm{n}^{\circ} 13$, de 29/6/2005, Diário Oficial da União, $\mathrm{n}^{\circ} 124$, de 30 de Junho de 2005.

2. http://www.abrabe.org.br/cachaca.php, acessada em Julho 2012.

3. Masson, J.; Cardoso, M. G.; Vilela, F. J.; Pimentel, F. A.; de Morais, A. R.; dos Anjos, J. P.; Ciênc. Agrotec. 2007, 31, 1805.

4. Lehtonen, M.; Jounela-Erikcsson, P. Em Flavour of Distilled Beverages: Origin and Development; Piggott, J. R., ed.; Verlag Chemie International Inc.: Florida, 1983, chap. 4.

5. De Maria, C. A. B.; Moreira, R. F. A.; Quim. Nova 2003, 26, 90.

6. Cleto, F. V. G.; Ravaneli, G. C.; Mutton, M. J. R.; Ciênc. Agrotec. 2009, 33, 1379.

7. Berry, D. R. Em Progress in Industrial Microbiology: Modern Applications of Traditional Biotechnologies; Bushell, M. E., ed.; Elsevier:
Amsterdam, 1984, chap. 3; Nykãnen, L.; Nykãnen, I. Em Volatile Compounds in Foods and Beverages; Maarse, H., ed.; Marcel Dekker Inc.: New York, 1991, chap. 15; Piggott, J. R.; Sharp, R.; Duncan, R. E. B.; The Science and Technology of Whiskies, Longman: New York, 1989.

8. Fennema, O. R.; Química de los Alimentos, Acribia: Zaragoza, 1993.

9. Nascimento, R. F.; Cardoso, D. R.; Lima-Neto, B. S.; Franco, D. W.; Quim. Nova 1998, 21, 735; Cardoso, D. R.; Lima-Neto, B. S.; Franco, D. W.; Quim. Nova 2003, 26, 165; Cardoso, D. R.; Bettin, S. M.; Reche, R. V.; Lima-Neto, B. S.; Franco, D. W.; J. Food Composition and Analysis 2003, 16, 563.

10. Moreira, R. F. A.; Trugo, L. C.; De Maria, C. A. B.; Quim. Nova 2000, 23, 195.

11. Patterson, R. L. S.; Charlwood, B. V.; Macleod, G.; Williams, A. A.; Bioformation of Flavours, The Royal Society of Chemistry: London, 1992.

12. Nóbrega, I. C. C.; Ciênc. Tecnol. Aliment. 2003, 23, 210 
13. Whiting, G. C.; J. Inst. Brewing. 1976, 82, 84; Berry, D. R. Em Fermented Beverage Production; Lea, A. G. H.; Piggott, J. R., eds.; Blackie Academic \& Professional: London, 1995, chap. 2.

14. Alves, G. L.; Cardello, H. M. A. B.; Faria, J. B.; Braz. J. Food Nutr. 2002, 13, 83; Miglio, G.; Branntweinwirtschaft 1971, 111, 381.

15. Dias, S.; Maia, A.; Nelson, D.; Ciênc. Tecnol. Aliment. 1998, 18, 331.

16. Vilela, F. J.; Cardoso, M. G.; Masson, J.; dos Anjos, J. P.; Ciênc. Agrotec. 2007, 31, 1089; Dato, M. C. F.; Júnior, J. M. P.; Mutton, M. J. R.; Braz. J. Microbiol. 2005, 36, 70.

17. Alcarde, A. R.; de Souza, P. A.; Belluco, A. E. S.; Ciênc. Tecnol. Aliment. 2011, 31, 355.

18. McMahon, D. M.; Winstead, S.; Weant, K. A.; Adv. Emerg. Nurs. J. 2009, 31, 206

19. Alcarde, A. R.; de Souza, P. A.; Belluco, A. E. S.; Sci. Agric. 2010, 67, 280.

20. Almeida, M. E. W.; Barreto, H. H. C.; Rev. Inst. Adolfo Lutz 1972, 31, 117; Zee, J. A.; Simard, R. E.; Carbillet, L.; Lebel, C.; Liber, E.; Lebensm.-Wiss.u.- Technol. 1984, 15, 54.

21. Amerine, M. A.; Ough, C. S.; Análisis de Vinos y Mostos, Acribia: Zaragoza, 1976.

22. Boscolo, M.; Bezerra, C. W. B.; Cardoso, D. R.; Lima-Neto, B. S.; Franco, D. W.; J. Braz. Chem. Soc. 2000, 11, 86.

23. Caruso, M. S. F.; Nagato, L. A. F.; Alaburda, J.; Rev. Inst. Adolfo Lutz. 2008, 67, 28.

24. Nascimento, R. F.; Tese de Doutorado, Universidade de São Paulo, Brasil, 1997; Nascimento, R. F.; Cerroni, J. L.; Cardoso, D. R.; LimaNeto, B. S.; Franco D. W.; Ciênc. Tecnol. Aliment. 1998, 18, 350.

25. He, R.; Lu, J.; Miao, J.; Sci. China Life Sci. 2010, 53, 1399; Setshedi, M.; Wands, J. R.; Monte, S. M.; Oxid. Med. Cell Longev. 2010, 3, 178; Jaganjac, M.; Prah, I. O.; Cipak, A.; Cindric, M.; Mrakovcic, L.; Tatzber, F.; IIincic, P.; Rukavina, V.; Spehar, B.; Vukovic, J. P.; Telen, S.; Uchida, K.; Lulic, Z.; Zarkovic, N.; Environ. Toxicol. (2011), doi:10.1002/ tox. 20683.

26. Amoore, J. E.; Hautala, E.; J. Appl. Toxicol. 1983, 3, 272; Nikfardjam, M. P.; Maier, D.; Food Chem. 2011, 126, 1926.

27. Parazzi, C.; Arthur, C. M.; Lopes, J. J. C.; Borges, M. T. M. R.; Ciênc. Tecnol. Aliment. 2008, 28, 193.

28. Culleré. L.; Ferreira, V.; Cacho, J.; Food Chem. 2011, 127, 1397.

29. de Andrade, J. B.; Bravo, R. V. F.; Quim. Nova 1989, 12, 196.

30. Liebich, H. M.; Koening, W. A.; J. Chromatogr. Sci. 1970, 8, 527; Puputti, E.; Lethonen, P.; J. Chromatogr., A 1986, 353, 164; Benn, S. W.; Peppard, T. R.; J. Agric. Food Chem. 1996, 44, 557.

31. Pinheiro, P. C.; Leal, M. C.; de Araújo, D. A.; Química Nova na Escola 2003, n. 18, 3

32. Buttery, R. G.; Turnbaugh, J. G.; Ling, L. C.; J. Agric. Food Chem. 1988, 36, 1006; Yasuhara, A.; J. Chromatography 1987, 387, 371; Kalua, C. M.; Allen, M. S.; Bedgood Jr., D. R.; Bishop, A. G.; Prenzler, P. D.; Robards, K.; Food Chem. 2007, 100, 273; Dragone, G.; Mussatto, S. I.; Oliveira, J. M.; Teixeira, J. A.; Food Chem. 2009, 112, 929.

33. de Nascimento, R. F.; Cardoso, D. R.; Lima-Neto, B. S.; Franco, D. W.; Chromatographia 1998, 48, 751.

34. Nascimento, R. F.; Cardoso, D. R.; Keukeleire, D.; Lima-Neto, B. S.; Franco, D. W.; J. Agric. Food Chem. 2000, 48, 6070.

35. Serafim, F. A. T.; Buchviser, S. F.; Galinaro, C. A.; Novaes, F. V.; Franco, D. W.; Quim. Nova 2011, 34, 28.

36. Nascimento, E. S. P.; Cardoso, D. R.; Franco, D. W.; J. Agric. Food Chem. 2008, 56, 5488; Nascimento, E. S. P.; Cardoso, D. R.; Franco, D. W.; Quim. Nova 2009, 32, 2323.

37. Geddes, P. A.; Riffkin, H. L. Em Distilled Beverage Flavour: Recent Developments; Piggott, J. R.; Paterson, A., eds.; VCH: New York, 1989, chap. 17.
38. Suomalainen, H.; Lehtonen, M.; J. Inst. Brewing. 1979, 85, 149

39. Lurton, L.; Snakkers, G.; Roulland, C.; Galy, B.; J. Sci. Food Agric. 1995, 67, 485; Rossiter, K. J.; Chem. Rev. 1996, 96, 3201; Lee, K. Y. M.; Paterson, A.; Piggott, J. R.; Richardson, G. D.; J. Inst. Brewing. 2001, 107, 287; De Souza, M. D. C. A.; Vásquez, P.; Del Mastro, N. L.; Lavin, E. H.; Acree, T. E.; J. Agric. Food Chem. 2006, 54, 485.

40. Faria, J. B.; Deliza, R.; Rossi, E. A.; Ciênc. Tecnol. Aliment. 1993, 13, 89; Isique, W. D.; Cardello, H. M. A. B.; Faria, J. B.; Ciênc. Tecnol. Aliment. 1998, 18, 169

41. Masuda, M.; Nishimura, K.; J. Food Sci. 1982, 47, 101; Tamaki, T.; Takamiya, Y.; Takaesu, C.; Nishiya, T.; J. Ferm. Technol. 1986, 64, 129.

42. Miranda, M. B.; Martins, N. G. S.; Belluco, A. E. S.; Horii, J.; Alcarde, A. R.; Ciênc. Tecnol. Aliment. 2008, 28 (Supl.), 84.

43. Netto, C. C.; Moreira, R. F. A.; de Maria, C. A. B.; Food Sci. Technol. Int. 2003, 9, 359.

44. NyKänen, L.; NyKänen, I. Em Flavour of Distilled Beverages: Origin and Develppment; Piggott, J., ed.; Ellis Horwood Ltd.: Chichester, 1983; Pino, J. A.; Alimentaria 1996, 33, 79.

45. da Silva, A. A.; Nascimento, E. S. P.; Cardoso, D. R.; Franco, D. W.; J. Sep. Sci. 2009, 32, 3681.

46. Delgado, T.; Gomez-Cordovi, S. C.; Villarroya, B.; Am. J. Enol. Vitic. 1990, $41,342$.

47. Parrilla, G. M. C.; Heredia, F. J.; Troncoso, A. M.; Food Res. Int. 1999 , 32, 433; Faria, J. B.; Cardello, H. M. A. B.; Boscolo, M.; Isique, W. D.; Odello, L.; Franco, D. W.; Eur. Food. Res. Technol. 2003, 218, 83.

48. Cardello, H. M. A. B.; Faria, J. B.; Ciênc. Tecnol. Aliment. 1998, 18 , 169.

49. Reazin, G. H.; Am. J. Enol. Vit. 1981, 32, 283; Nishimura, K.; Matsuyama, R. Em The Science and Technology of Whiskies; Piggott, J. R.; Sharp, R.; Duncan, R. E. B., eds.; Longman Scientific \& Technical: New York, 1989, chap. 8; Puech, J. L.; Rabier, P.; Bories-Azeau, J.; Sarni, F.; Moutounet, M.; J. Assoc. Off. Anal. Chem. 1990, 73, 498.

50. http://www.chemicalbook.com/indexEN.aspx, acessada em Julho 2012.

51. http://www.flavornet.org/flavornet.html, acessada em Julho 2012.

52. Iwasaki, Y.; Ishiguro, T.; Japan Society Atmospheric Environment 1978 , 13,34 .

53. Buttery, R. G.; Seifert, R. M.; Guadagni, D. G.; Ling, L. C.; J. Agric. Food Chem. 1971, 19, 524.

54. Merck Research Laboratories; The Merck Index - An Encyclopedia of Chemicals, Drugs, and Biologicals, $13^{\text {th }}$ ed., Merck \& Co., Inc: New Jersey, 2001.

55. Guth, H.; J. Agric. Food Chem. 1997, 45, 3027.

56. Dragone, G.; Mussatto, S. I.; Oliveira, J. M.; Teixeira, J. A.; Food Chem. 2009, 112, 929

57. Mamede, M. E. O.; Pastore, G. M.; Ciênc. Tecnol. Aliment. 2007, 27, 281.

58. Caruso, M. S. F; Nagato, L. A. F.; Alaburda, J.; Rev. Inst. Adolfo Lutz 2008, 67, 28

59. Leffingwell, J. C.; Leffingwell, D.; Perfumer \& Flavorist 1991, 16, 1.

60. Reche, R. V.; Neto, A. F. L.; Da Silva, A. A.; Galinaro, C. A.; De Osti, R. Z.; Franco, D. W.; J. Agric. Food Chem. 2007, 55, 6603.

61. Blank, I. Em Techniques for Analyzing Food Aroma; Marsili, R., ed.; Marcel Dekker: New York, 1996, chap. 10

62. Janzantti, N. S.; Tese de Doutorado, Universidade Estadual de Campinas, Brasil, 2004.

63. Toledo, J. F. A.; Faria, J. B.; Alim. Nutr. 2004, 15, 51.

64. Collin, S.; Nizet, S.; Bouuaert, T. C.; Despatures, P. M.; J. Agric. Food Chem. 2012, 60, 380. 